\title{
Induction of autophagy protects human dental pulp cells from lipopolysaccharide-induced pyroptotic cell death
}

\author{
YANG GAO ${ }^{1-3^{*}}$, XINRAN YOU ${ }^{4 *}$, YUBO LIU $^{5}$, FEI GAO ${ }^{4}$, \\ YUAN ZHANG $^{6}$, JIANRONG YANG ${ }^{1,2}$ and $\mathrm{CHEN} \mathrm{YANG}^{4}$ \\ ${ }^{1}$ Jiangsu Key Laboratory of Oral Disease; ${ }^{2}$ Department of Oral and Maxillofacial Surgery, The Affiliated Hospital of \\ Stomatology, Nanjing Medical University, Nanjing, Jiangsu 210029; ${ }^{3}$ Department of Stomatology, The First \\ Affiliated Hospital of Soochow University, Suzhou, Jiangsu 215000; Departments of ${ }^{4}$ Nuclear Medicine and \\ ${ }^{5}$ Orthopedics, The Affiliated Suzhou Hospital of Nanjing Medical University, Suzhou, Jiangsu 215002; \\ ${ }^{6}$ Department of Head and Neck Oncology, The Affiliated Jiangsu Cancer Hospital of \\ Nanjing Medical University, Nanjing, Jiangsu 210009, P.R. China
}

Received February 23, 2019; Accepted November 1, 2019

DOI: $10.3892 /$ etm.2020.8475

\begin{abstract}
The NOD-like receptor protein 3/caspase-1 inflammasome can be activated in human dental pulp tissue and fibroblasts; however, the underlying mechanisms are poorly understood. In the present study, lipopolysaccharide (LPS) was used to treat dental pulp cells to establish an inflammation model. Cell viability was examined by sulforhodamine $B$ assay. Interleukin (IL)-1 $\beta$, caspase-1, microtubule-associated protein-1 light chain 3-II/I and p62 were determined by western blotting and ELISA. The phosphorylation (p-) levels of NF- $\kappa \mathrm{B}$ and $\mathrm{NF}-\kappa \mathrm{B}$ inhibitor $(\mathrm{I} \kappa \mathrm{B}) \alpha$ protein were observed by western blotting. The results demonstrated that LPS induced pyroptotic cell death in cultured dental pulp cells, which was supported by the increased levels of IL-1 $\beta$, IL-18 and caspase-1. Rapamycin and 3-methyladenine (3-MA) were used to activate and inhibit autophagy, and it was observed that LPS increased autophagy and rapamycin reduced LPS-induced dental pulp cell pyroptosis. However, 3-MA aggravated LPS-induced dental pulp cell pyroptosis. In addition, LPS inhibited the expression of $\mathrm{I} \kappa \mathrm{B} \alpha$, but increased the expression of $\mathrm{p}-\mathrm{NF}-\kappa \mathrm{B}$. Compared
\end{abstract}

Correspondence to: Dr Jianrong Yang, Jiangsu Key Laboratory of Oral Disease, The Affiliated Hospital of Stomatology, Nanjing Medical University, 136 Hanzhong Road, Nanjing, Jiangsu 210029, P.R. China

E-mail: yjrong_yangc@163.com

Dr Chen Yang, Department of Nuclear Medicine, The Affiliated Suzhou Hospital of Nanjing Medical University, 26 Daoqian Street, Suzhou, Jiangsu 215002, P.R. China

E-mail: chyang_yach@163.com

*Contributed equally

Key words: dental pulp cells, lipopolysaccharide, pyroptosis, autophagy, NF- $\kappa \mathrm{B}$ with the LPS group, 3-MA further inhibited the expression of $\mathrm{I} \kappa \mathrm{B} \alpha$ but promoted the expression of $\mathrm{p}-\mathrm{NF}-\kappa \mathrm{B}$. However, rapamycin produced the opposite results to LPS. Under LPS treatment, the NF- $\kappa$ B pathway inhibitor BAY11-7082 further enhanced the inhibitory effects of rapamycin, but inhibited the promoting effects of 3-MA on the protein expression levels of IL-1 $\beta$ and caspase- 1 . The results of the present study demonstrated that there is an important crosstalk between autophagy, pyroptosis and the NF- $\kappa \mathrm{B}$ pathway, and that the modulation of pyroptosis in dental pulp cells may be a promising strategy to pulpitis therapy.

\section{Introduction}

Caries bacteria are a major cause of dental pulpal inflammation and infection (1), and the dental pulp is surrounded by a rigid physical barrier that resists pathogenic challenges (2). The integrity of the barrier undergoes inevitable and irreversible changes due to adverse conditions such as aging, and the caries bacteria and their products penetrate into the pulp tissue if the integrity of the barrier is damaged (2). Gram-negative anaerobic bacteria become dominant in the microflora as carious infection progresses to the pulp-dentin interface (3). Lipopolysaccharide (LPS), the major cell wall component of gram-negative bacteria, is widely used as a pathogen-associated molecule to mimic clinical pathological conditions $(4,5)$. Studies have increasingly demonstrated that cell death is caused by apoptosis, necrosis or pyroptosis, which can be induced by inflammation $(6,7)$. These findings suggest that bacterial infections may trigger an inflammatory response that can lead to cell death.

Pyroptosis, often referred to as inflammatory cell death, induces the release of inflammatory cytokines interleukin (IL) $1 \beta$ and IL-18 by activating inflammatory complexes composed of caspase-1 (8). NOD-like receptor protein 3 (NLRP3) inflammasome-mediated caspase-1 activation and the subsequent secretion of pro-inflammatory cytokines including IL-1 $\beta$ and IL-18 are markers for pyroptosis (9). 
NLRP3 inflammasome has been reported to be expressed in dental pulp tissue (10). However, whether the NLRP3 inflammasome/caspase-1/IL-1 $\beta /$ IL-18 signaling pathway in dental pulp cells is activated during dental pulp inflammation has not yet been investigated to the best of the authors knowledge. The NF- $\mathrm{NB}$ family of inducible transcription factors serve an essential role in different aspects of immune responses (11). A previous study has demonstrated that the activation of $\mathrm{NF}-\kappa \mathrm{B}$ may promote the transcriptional expression

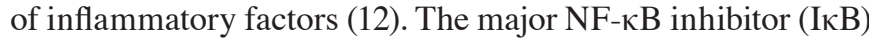
family member that regulates the classical $N F-\kappa B$ pathway is $\mathrm{I} \kappa \mathrm{B} \alpha$, which is characterized by its dynamic changes and signal-induced $\mathrm{NF}-\kappa \mathrm{B}$ activation (11). Thus, targeting the $\mathrm{NF}-\kappa \mathrm{B}$ pathway may be an effective therapy for dental pulpal inflammation.

As a highly conserved catabolic pathway, autophagy is involved in multiple pathological conditions and in numerous physiological processes including cell death (13) and differentiation (14), neurodegeneration (15), immunity (16) and organ development $(17,18)$. Previous studies have also revealed that autophagy participates in odontoblast aging (19) and tooth development (20). Autophagy is usually accompanied by changes in microtubule-associated protein 1 light chain 3 (LC3) $\alpha$ and p62 (21,22). Autophagy exerts protective roles in the early stage of inflamed odontoblasts, whereas the over-induction of autophagy leads to odontoblast cell death (23). LPS can stimulate autophagy in endothelial cells, cardiomyocytes and macrophages (24-26); however, the effects of autophagy on LPS-induced cytotoxicity and whether autophagy in dental pulp cells could be activated by LPS have yet to be investigated.

The present study hypothesized that LPS induced NLRP3/caspase-1-dependent pyroptosis in dental pulp cells, which may be inhibited by autophagy and the NF- $\kappa \mathrm{B}$ signaling pathway. Therefore, the aims of the present study were to: i) Investigate whether pyroptosis in dental pulp cells was activated in response to LPS; and ii) elucidate the effects of autophagy during the process and determine if the $\mathrm{NF}-\kappa \mathrm{B}$ signal pathway was involved.

\section{Materials and methods}

Cell isolation, culture and identification. As described previously (27), human dental pulp cells were isolated from intact, caries-free supernumerary teeth that had been freshly extracted from six healthy children aged between 7 and 10 years old. The study protocol was approved by the Ethical Committee of Nanjing Medical University (approval no. NM20180510). Written informed consent was obtained from the children's parents or legal representatives. The teeth were maintained in phosphate buffer saline (PBS) and split open following extraction. Under sterile conditions, the dental pulp tissues were removed and minced using a surgical knife, transferred to a centrifuge tube and centrifuged at $300 \mathrm{x}$ g for $5 \mathrm{~min}$ at room temperature. The supernatant was removed and the sample was incubated at $37^{\circ} \mathrm{C}$ for 45 min with type I collagen and centrifuged again at $300 \mathrm{x}$ g for $5 \mathrm{~min}$ at room temperature. Following removal of the supernatant, the sample was washed three times with $\alpha$-MEM medium (Gibco; Thermo Fisher Scientific, Inc.) containing 10\% fetal bovine serum (FBS;
Gibco; Thermo Fisher Scientific, Inc.) and centrifuged at $300 \mathrm{x}$ g for $5 \mathrm{~min}$ at room temperature. The obtained cells were suspended in a-MEM medium containing $20 \% \mathrm{FBS}$, seeded in cell culture bottles and incubated at $37^{\circ} \mathrm{C}$ with $5 \% \mathrm{CO}_{2}$.

Dental pulp cells at the logarithmic growth phase at the third passage were washed with PBS twice and digested with PBS containing $0.25 \%$ trypsin for single-cell suspension preparation. The cell suspension $(100 \mu \mathrm{l})$ was added to an Eppendorf tube $\left(3 \times 10^{9}\right.$ cells/tube $)$ and incubated with rat-anti-human monoclonal antibodies CD29-PE (cat.no.bs-0486R-PE; 1:100), CD105-PE (cat.no.bs-0579R-PE; 1:100), CD146-PE (cat. no. bs-1618R-PE; 1:100), CD34-PE (cat. no. bs-0646R-PE; 1:100), CD45-PE (cat. no. bs-0522R-PE; 1:100), CD90-PE (cat. no. bs-0778R-PE; 1:100; all from Bioss Biotechnology Co., Ltd.) and rat-anti-human STRO-1 (cat. no. ab214086; 1:500; Abcam) at $4^{\circ} \mathrm{C}$ for $30 \mathrm{~min}$, followed by incubation for $15 \mathrm{~min}$ in the dark, washing with PBS, centrifugation at $300 \mathrm{x} \mathrm{g}$ for $5 \mathrm{~min}$ at room temperature, suspension and fixation with PBS containing $1 \%$ paraformaldehyde. Background markers were identified using homotype controlled monoclonal antibodies. Flow cytometry (Becton, Dickinson and Company) and FlowJo software version 7.6.2 (FlowJo LLC) were used to analyze the cells. According to the results, the cells with the best purity, defined as the highest positive cell surface antigen rate, were selected for subsequent experiments.

Pure dental pulp cells at passages 3 to 4 were used for drug treatment. Briefly, different concentration of LPS $(0,10,100$, 200, 300, 500 and 1,000 $\mu \mathrm{g} / \mathrm{l})$, rapamycin ( $2 \mu \mathrm{M})$, 3-methyladenine (3-MA; $10 \mathrm{mM}$ ) and BAY11-7082 (2.5 $\mu \mathrm{M}$; all from Sigma-Aldrich; Merck KGaA) were used to pretreat the dental pulp cells for $72 \mathrm{~h}$.

Western blot analysis. Western blot analysis was conducted as previously described (28). The total protein was extracted from human dental pulp cells $\left(2 \times 10^{6}\right)$ using RIPA lysis buffer containing Halt Protease and Phosphatase Inhibitor Cocktail (Pierce; Thermo Fisher Scientific, Inc.). Bicinchoninic acid protein assay kit (Pierce; Thermo Fisher Scientific, Inc.) was applied to determine the protein concentration. Proteins (30 $\mu \mathrm{g}$ /lane) were separated by SDS-PAGE (10\% gel) and transferred to a PVDF membrane (Bio-Rad Laboratories, Inc.). The membrane was blocked with 5\% skim milk in PBS-Tween-20 for $2 \mathrm{~h}$. Membranes were incubated primary antibodies overnight at $4{ }^{\circ} \mathrm{C}$, and with secondary antibodies for $2 \mathrm{~h}$ at room temperature. In addition, to detect the protein expression of IL-1 $\beta$, cell culture media were collected and the proteins in the media were precipitated using trichloroacetic acid protein precipitation method as previously described (29). The band signal was developed using an Enhanced Chemiluminescence kit (Beyotime Institute of Biotechnology) and exposed to X-ray film. The relative quantity of proteins was determined by Image $\mathrm{J}$ (version 1.47; National Institutes of Health) and normalized to loading controls. The antibodies used were as follows: Anti- $\beta$-tubulin $(50 \mathrm{kDa}$; rabbit; 1:1,000; cat. no. ab6046; Abcam), anti-IL-1 $\beta$ (17 kDa; rabbit; 1:1,000; cat. no. 12703; Cell Signaling Technology, Inc.), anti-pro-IL-1 $\beta$ (17 kDa; rabbit; 1:1,000; cat. no. 83186; Cell Signaling Technology, Inc.), anti-caspase-1 (45 kDa; rabbit; 1:1,000; cat. no. ab74279; Abcam), anti-pro-caspase-1 
(20/22 kDa; rabbit; 1:1,000; cat. no. 4199; Cell Signaling Technology, Inc.), anti-phosphorylated (p-)NF-кB (65 kDa; rabbit; 1:1,000; cat. no. 3039; Cell Signaling Technology, Inc.), anti-NF- $\mathrm{BB}$ (65 kDa; rabbit; 1:1,000; cat. no. 8242; Cell Signaling Technology, Inc.), anti-I $\kappa \mathrm{B} \alpha$ (36 kDa; rabbit; 1:1,000; cat. no. ab32518; Abcam), anti-p62 (62 kDa; mouse; 1:1,000; cat. no. ab56416; Abcam) and anti-LC3-II/LC3-I ( 16 and $\sim 18 \mathrm{kDa}$; rabbit; 1:1,000; cat. no. ab51520; Abcam), and the secondary antibodies were horseradish peroxidase-conjugated goat anti-mouse/rabbit IgG (1:2,000; sc-516102/ sc-2357; Santa Cruz Biotechnology, Inc.).

ELISA. The cultured supernatant IL-18 content was determined by ELISA using a human IL-18 kit (cat. no. SEA064Hu; USCN Life Sciences, Inc.). The assay was performed according to the manufacturer's instructions and the results were calculated relative to standard curves prepared for IL-18.

Cell viability. Cell viability was determined by sulforhodamine B (SRB) assay (cat. no. 230162, Sigma-Aldrich; Merck KGaA). Briefly, the dental pulp cells were seeded in 96 -well plates at a density $1 \times 10^{6}$ cells $/ \mathrm{ml}$ and cultured to $\sim 70-80 \%$ confluence. Next, the cells were fixed with $50 \%$ trichloroacetic acid at $4^{\circ} \mathrm{C}$ for $1 \mathrm{~h}$ and stained by $0.4 \%$ SRB solution for $30 \mathrm{~min}$ at room temperature. SRB was measured as the absorbance at $565 \mathrm{~nm}$ using a Bio-Rad microplate reader (Bio-Rad Laboratories, Inc.).

Statistical analysis. Data are presented as the mean \pm SEM. GraphPad Prism 7 (GraphPad Software, Inc.) was used for statistical analysis. Statistical comparisons between two and among multiple groups were performed using Student's t-test and one-way analysis of variance followed by Dunnett's test, respectively. $\mathrm{P}<0.05$ was considered to indicate a statistically significant difference.

\section{Results}

Pyroptotic cell death is induced by LPS in cultured dental pulp cells. Human dental pulp cells were examined by flow cytometry, and the results demonstrated that these cells were positive for CD29, CD90, CD105, CD146 and STRO-1, but negative for the cell surface antigens CD34 and CD45 (Fig. 1A). These surface antigens were consistent with those expressed on dental pulp cells in a previous study (30), indicating that human dental pulp cells were successfully cultured and isolated in the current study. The effect of LPS stimulation on dental pulp cells were investigated by SRB assay after treating the cells with different concentrations of LPS for $72 \mathrm{~h}$; the results demonstrated that LPS reduced cell viability in a concentration-dependent manner (Fig. 1B). When the cells were treated with $300 \mu \mathrm{g} / 1 \mathrm{LPS}$, cell viability significantly decreased $(\mathrm{P}<0.01)$; thus $300 \mu \mathrm{g} / \mathrm{l} \mathrm{LPS}$ was selected for subsequent experiments. A significant decrease in dental pulp cell viability was observed in the LPS group at $72 \mathrm{~h}$ compared with the control group (Fig. 1C). The secretion levels of the pyroptosis markers IL-1 $\beta$ and IL-18 and caspase- 1 activation were assessed by western blotting and ELISA following LPS treatment for 24, 48 and $72 \mathrm{~h}$. Western blot assay results demonstrated that LPS upregulated the protein levels of extracellular IL-1 $\beta$ (Fig. 1D) and caspase-1 (Fig. 1E) in a time-dependent manner without affecting the accumulation of pro-IL-1 $\beta$ (Fig. 1F) and pro-caspase-1 (Fig. 1G) in the dental pulp cells (Fig. 1H). Similarly, ELISA assay data demonstrated that LPS increased the extracellular content of IL-18 at 48 and $72 \mathrm{~h}$ (Fig. 1I). These results demonstrated that LPS increased the extracellular secretion of IL-1 $\beta$ and IL-18 and caspase-1 activation, suggesting that LPS may induce pyroptotic cell death in cultured dental pulp cells. Based on these results, $72 \mathrm{~h}$ was selected as the treatment duration for the following experiments.

Autophagy is activated by LPS. To study the effect of LPS stimulation on dental pulp cell autophagy and whether chemical modulators of autophagy may regulate the autophagy of dental pulp cells under LPS treatment, the protein levels of autophagy markers LC3 and p62 were determined by western blotting (Fig. 2A). The results revealed that under LPS stimulation, the ratio of LC3-II/LC3-I protein levels was increased with notable upregulation of LC3-II compared with the control group (Fig. 2B and C); however, p62 accumulation was slightly decreased (Fig. 2A and D). In addition, the LC3-II/LC3-I ratio was increased and LC3-II content and p62 were further upregulated by rapamycin treatment, whereas 3-MA treatment produced opposite effects to rapamycin (Fig. 2), indicating that rapamycin induced autophagy, whereas 3-MA inhibited autophagy in dental pulp cells under LPS treatment.

LPS-induced pyroptotic cell death is suppressed by autophagy. Autophagy is activated by LPS; however, its role in pyroptotic cell death is unclear. Therefore, the effects of rapamycin and 3-MA on pyroptotic cell death and the viability of dental pulp cells were investigated under LPS treatment. Pyroptotic characteristics such as IL-1 $\beta$ (Fig. 3A and B) and IL-18 secretion (Fig. 3F), as well as caspase-1 activation (Fig. 3A and C) in the LPS group were significantly inhibited by rapamycin, but enhanced by 3-MA without affecting the levels of pro-IL-1 $\beta$ (Fig. 3A and D) and pro-caspase-1 (Fig. 3A and E). Consistently, SRB assay results demonstrated that rapamycin treatment significantly attenuated the LPS-induced decrease in dental pulp cell viability, whereas 3-MA pretreatment exerted an opposite effect (Fig. 3G).

Autophagy inhibits LPS-induced pyroptotic death of dental pulp cells by regulating the $N F-\kappa B$ signaling pathway. To detect whether autophagy inhibited LPS-induced pyroptotic dental pulp cell death by regulating the $N F-\kappa B$ signaling pathway, the levels of $p-N F-\kappa B, N F-\kappa B$ and $\mathrm{I} \kappa \mathrm{B} \alpha$ were determined by western blot assay, and the $N F-\kappa B$ signaling pathway inhibitor BAY11-7082 was used. Under LPS stimulation, the protein level of $\mathrm{p}-\mathrm{NF}-\kappa \mathrm{B}$ was significantly upregulated, whereas that of $\mathrm{I} \kappa \mathrm{B} \alpha$ was downregulated in dental pulp cells compared with that in the control group, and this effect was further enhanced by 3-MA, but weakened by rapamycin (Fig. 4A and B). No significant difference was observed in the expression of NF- $\mathrm{NB}$ among all groups. Under BAY11-7082 and LPS treatment, there was an evident decrease in the elevated IL-1 $\beta$ and caspase- 1 activation induced by LPS. Of 

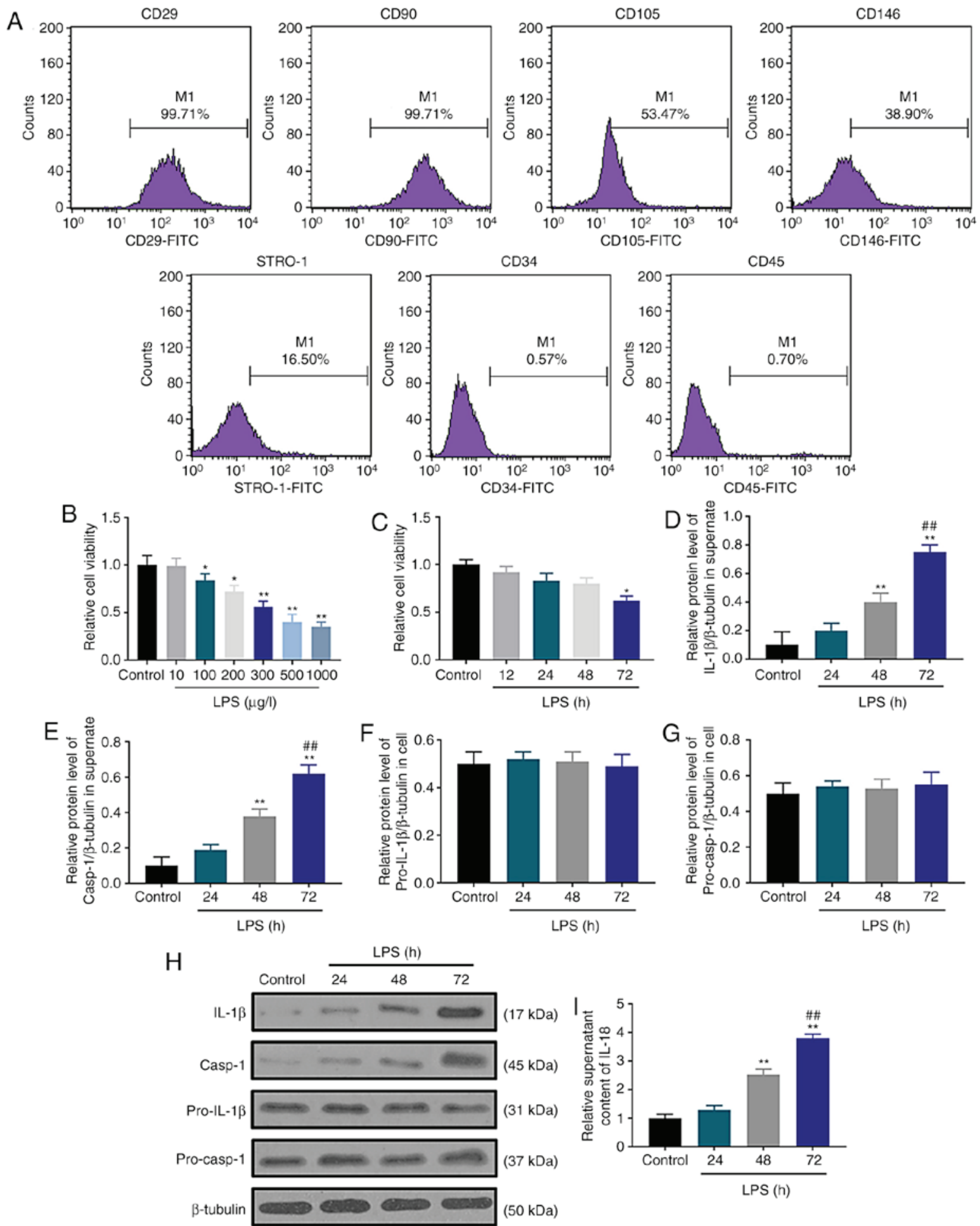

Figure 1. Pyroptotic cell death is induced by LPS in cultured dental pulp cells. (A) Human dental pulp cell surface marker expression was examined using flow cytometry. (B) Effects of different concentrations of LPS $(0,10,100,200,300,500$ and 1,000 $\mu \mathrm{g} / \mathrm{l})$ on human dental pulp cell viability. (C) Human dental pulp cell viability was inhibited by LPS as determined by sulforhodamine B assay. (D and E) The protein levels of (D) IL-1 $\beta$ and (E) caspase-1 were normalized to that of $\beta$-tubulin. (F and $\mathrm{G}$ ) The protein levels of (F) (pro)-IL-1 $\beta$ and $(\mathrm{G})$ (pro)-caspase-1 were normalized to that of $\beta$-tubulin. (H) Western blot assay was used to detect the contents of IL- $1 \beta$, caspase-1, pro-IL-1 $\beta$ and pro-caspase-1. (I) IL-18 contents were determined by ELISA. ${ }^{*} \mathrm{P}<0.05$ and ${ }^{* *} \mathrm{P}<0.01$ vs. control; ${ }^{\# \#} \mathrm{P}<0.01$ vs. 48 h. LPS, lipopolysaccharide; IL, interleukin.

note, rapamycin inhibited the elevation of IL-1 $\beta$ and caspase-1 activation induced by LPS, and these inhibitory effects were further enhanced by BAY11-7082 (Fig. 4C-E). 3-MA promoted LPS-induced IL-1 $\beta$ elevation and caspase-1 activation, which was partially reversed by BAY11-7082 (Fig. 4C-E). In addition, the results demonstrated that BAY11-7082 partially reversed the decreased dental pulp cell viability induced by LPS; BAY11-7082 further increased the promoting effects of rapamycin on dental pulp cell viability, but attenuated the inhibitory effect of 3-MA on cell viability (Fig. 4F). 

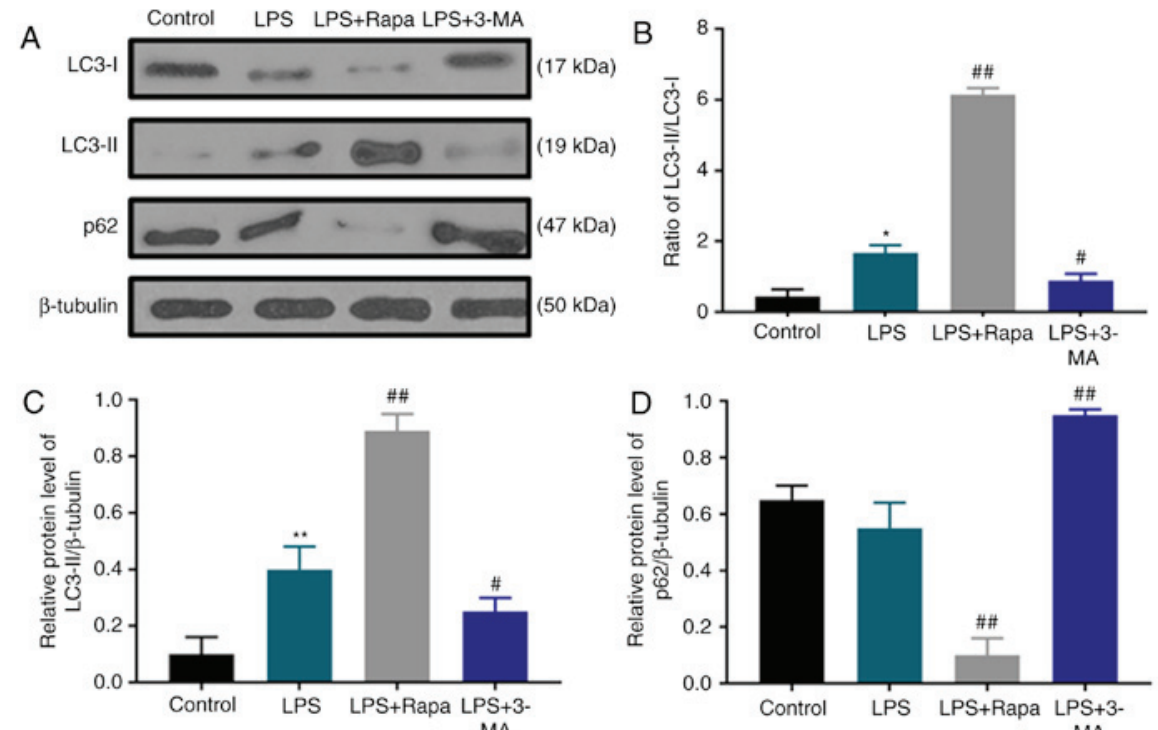

Figure 2. Autophagy is activated by LPS. (A) Western blot analysis of autophagy-related proteins LC3 and p62. (B) The LC3-II/LC3-I ratio was determined based on densitometric analysis of the bands shown in (A). (C) LC3-II protein level was quantified based on densitometry analysis of bands shown in (A). (D) The P62 protein level was quantified based on densitometry analysis of bands shown in (A). ${ }^{*} \mathrm{P}<0.05$ and ${ }^{* *} \mathrm{P}<0.01$ vs. control; ${ }^{*} \mathrm{P}<0.05$ and ${ }^{\# \#} \mathrm{P}<0.01$ vs. LPS. LPS, lipopolysaccharide; LC3, microtubule-associated protein 1 light chain 3; Rapa, rapamycin; 3-MA, 3-methyladenine.
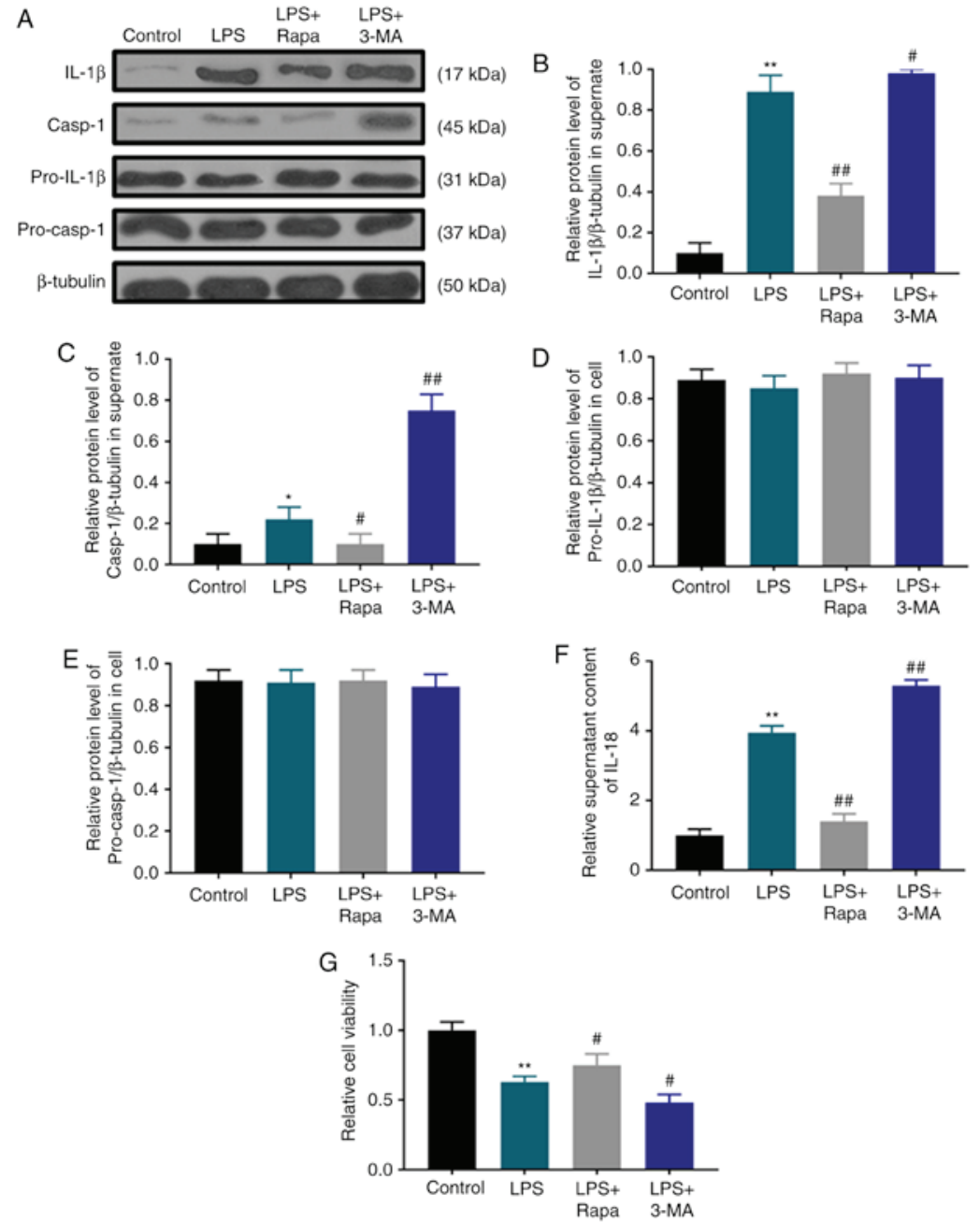

Figure 3. LPS-induced pyroptotic cell death is suppressed by autophagy. (A) Western blot assay was used to detect the contents of (pro)-IL-1 $\beta$ and (pro)-caspase-1. (B and C) The protein levels of (B) IL-1 $\beta$ and (C) caspase-1 were normalized to that of $\beta$-tubulin. (D and E) The protein levels of (D) pro-IL-1 $\beta$ and (E) pro-caspase-1 were normalized to that of $\beta$-tubulin. (F) IL-18 contents were determined by ELISA. (G) Human dental pulp cell viability was inhibited by LPS as revealed by sulforhodamine $B$ assay. ${ }^{*} \mathrm{P}<0.05$ and ${ }^{* *} \mathrm{P}<0.01$ vs. control; ${ }^{*} \mathrm{P}<0.05$ and $^{\# \#} \mathrm{P}<0.01$ vs. LPS. LPS, lipopolysaccharide; IL, interleukin; Rapa, rapamycin; 3-MA, 3-methyladenine. 
A
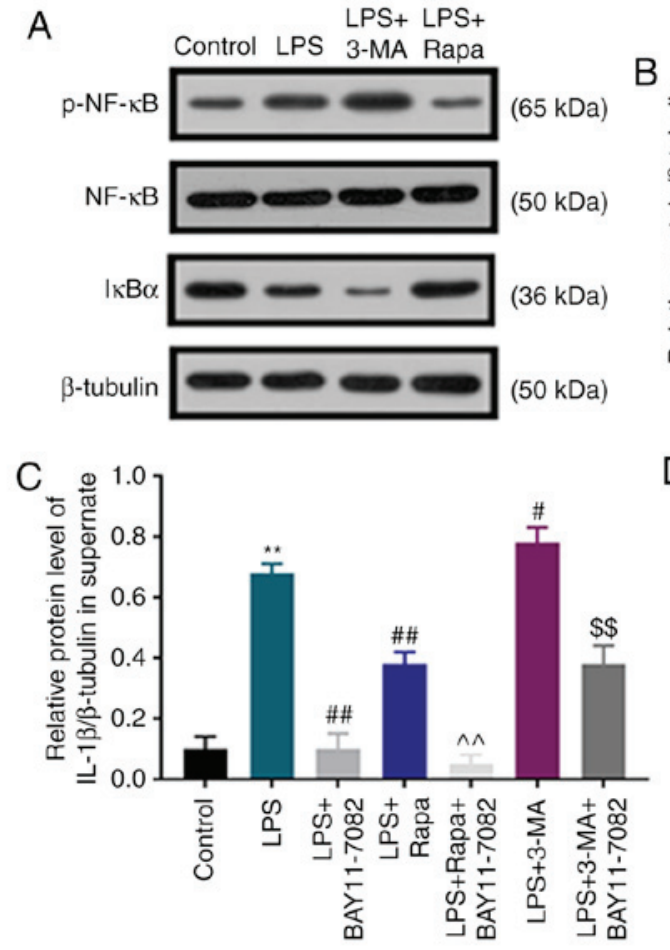
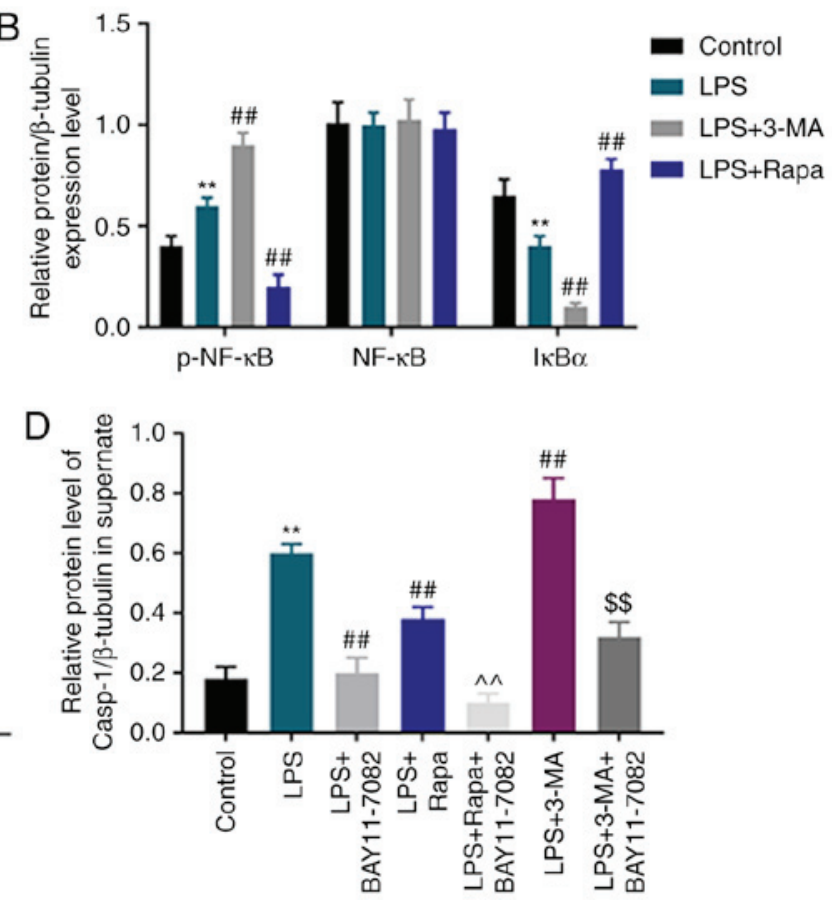
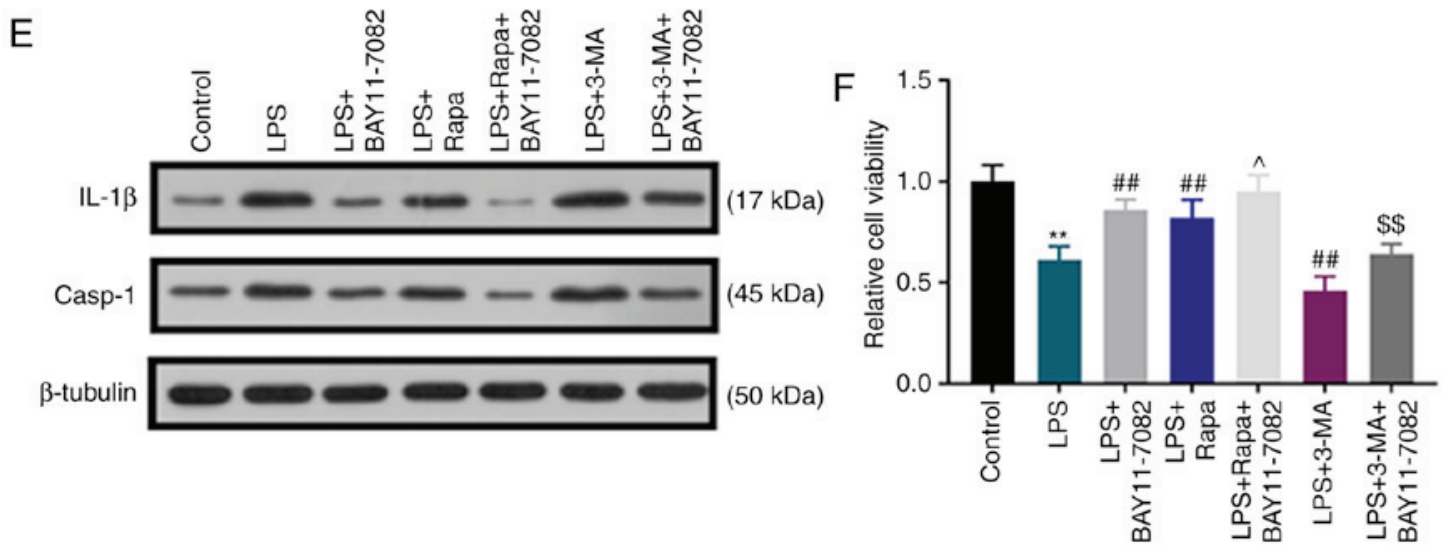

Figure 4. Autophagy inhibits LPS-induced pyrolytic dental pulp cell death by regulating the NF-kB signaling pathway. (A) Western blot assay was used to

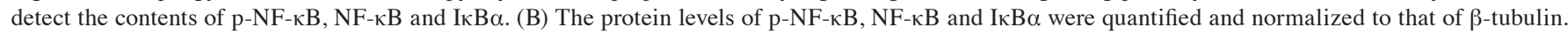
(C and D) The levels of (C) IL-1 $\beta$ and (D) caspase-1 were quantified and normalized to that of $\beta$-tubulin. (E) Western blot assay was used to detect IL-1 $\beta$ and caspase-1. (F) Human dental pulp cell viability was detected using sulforhodamine B assay. ${ }^{* * *} \mathrm{P}<0.01$ vs. control; $\mathrm{P}<0.05$ and ${ }^{\# \#} \mathrm{P}<0.01$ vs. LPS; ${ }^{\wedge} \mathrm{P}<0.05$ and

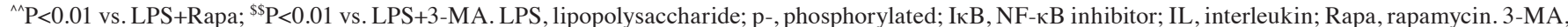
3-methyladenine.

\section{Discussion}

The present study investigated the role of pyroptotic cell death in inflamed dental pulp cells. The results demonstrated that LPS induced pyroptotic cell death in cultured dental pulp cells; this was inhibited by autophagy induction. In addition, autophagy was increased to a certain extent under LPS treatment, suggesting that the activation of autophagy may be a self-help measure in inflamed dental pulp cells, and the activation was enhanced by rapamycin-induced autophagy. Thus, it was hypothesized that rapamycin may be regarded as a potential drug candidate for inducing autophagy, which is likely to inhibit LPS-induced pyroptotic cell death in cultured dental pulp cells. The LPS-activated p-NF- $\mathrm{BB} / \mathrm{I} \kappa \mathrm{B} \alpha$ signaling pathway was inhibited by rapamycin-induced autophagy, whereas 3-MA-inhibited autophagy produced effects opposite to those of LPS.

Dental pulp cells are the primary targets for inflammatory agents, and the mechanism underlying dental pulp cell fate determination in an inflammatory microenvironment needs to be studied to protect dental pulp cells. To determine whether LPS-stimulated dental pulp cells induced inflammation, it was identified that pyroptosis-induced pro-inflammatory cytokines IL-1 $\beta$ and caspsase1 $(18,31,32)$ increased significantly as LPS treatment time increased, suggesting that LPS-stimulated dental pulp cells could mimic the pyroptotic death of dental pulp cells; these were therefore used as a model for exploring the mechanism of pyroptotic dental cell death. Apoptosis-associated speck like protein (ASC) and NLRP3 are involved in the activation of caspase-1 $(33,34)$. Jiang et al (10) 
have reported that the NLRP3/caspase-1 pathway exhibits a biological role in the innate immune response mounted by human dental pulp fibroblasts. In the present study, LPS activated caspase- 1 in dental pulp cells, which is associated with the formation of NLRP3 inflammatory corpuscles (3). Further activation of the inflammasome induces pyroptosis (35). However, in present study, the expression of NLRP3 and ASC were not examined; this is a limitation and requires further study.

Several studies have determined the expression levels of autophagy molecules in aging human odontoblast and dental pulp cells (36-39). It has been reported that autophagy induction serves a protective role against hypoxic stress in human dental pulp cells (40). Increased levels of autophagy molecules including ATG5, LC3-II and Beclin-1 have been identified in adult human dental pulp, especially in aged pulp cells (41). Under LPS stimulation, autophagy-related molecules are differentially expressed in adult pulp tissue and aged human dental pulp cells (39). In the current study, the ratio of LC3-II/LC3-I was increased following LPS treatment. Autophagy agonist rapamycin further increased the ratio of LC3-II/LC3-I, whereas the inhibition of autophagy by 3-MA reversed these effects. The results also demonstrated that rapamycin inhibited the elevation of IL-1 $\beta$, caspase- 1 and IL-18 following LPS stimulation, whereas 3-MA generated opposite effects to those of LPS. These results demonstrated that autophagy was activated in LPS-treated dental pulp cells and that targeting autophagy may be an effective therapy for dental pulpal inflammation.

$\mathrm{NF}-\kappa \mathrm{B}$ is an important transcription factor that regulates inflammation and is a part of an essential signaling pathway involved in the LPS-induced expression of cytokines (42). Previous studies have demonstrated that autophagy is required for the activation of $\mathrm{NF}-\kappa \mathrm{B}$ (43), and that $\mathrm{NF}-\kappa \mathrm{B}$ negatively regulates autophagy in specific cell types in vitro, including RAW 264.7 cells and bone marrow-derived macrophages upon brief coculture with E. coli (44). A previous study has suggested that rapamycin may suppress the generation of IL-1 $\beta$ and IL-18 in LPS-treated RAW264.7 cells by decreasing $\mathrm{NF}-\kappa \mathrm{B}$ signaling and increasing autophagy (45). In the present study, the $\mathrm{NF}-\kappa \mathrm{B} / \mathrm{I} \kappa \mathrm{B} \alpha$ signaling pathway was activated by LPS. The effects of 3-MA and rapamycin on the expression levels of $\mathrm{I} \kappa \mathrm{B} \alpha$ and $\mathrm{p}-\mathrm{NF}-\kappa \mathrm{B}$ were reversed by BAY11-7082, which is an $N F-\kappa B$ pathway inhibitor. These results demonstrated that autophagy may inhibit the LPS-induced pyrolysis death of dental pulp cells by regulating the $\mathrm{NF}-\kappa \mathrm{B}$ signaling pathway.

Rapamycin affects cell cycle, proliferation, autophagy and protein synthesis by suppressing mammalian target of rapamycin (mTOR) activity $(46,47)$. Previous studies have demonstrated that mTOR signaling serves a key role in mediating chronic inflammation and is involved in regulating inflammatory factors, including IL- $1 \beta$ and TNF- $\alpha(48,49)$. Rapamycin-induced inhibition of mTOR has been reported to significantly reduce the inflammation induced by various substances $(50,51)$. Previous studies have demonstrated that rapamycin exhibits anti-inflammatory actions by affecting $\mathrm{NF}-\kappa \mathrm{B}$ activity $(52,53)$. In the current study, rapamycin induced autophagy by regulating autophagy-related genes, such as LC3-II and p62. Rapamycin may inhibit the LPS-induced pyroptotic cell death by inhibiting the expression of IL-1 $\beta$ and regulating the $\mathrm{NF}-\kappa \mathrm{B} / \mathrm{I} \kappa \mathrm{B} \alpha$ signaling pathway.

However, the current study had certain limitations. For example, the effect of rapamycin-induced autophagy on LPS-mediated dental pulp cell pyroptosis was not verified in vivo. In addition, the present study was conducted on dental pulp cells from healthy teeth without comorbidities common in teeth susceptible to caries infection. Although the aim of the current study was to explore whether rapamycin-induced autophagy may produce protective effects against LPS-mediated dental pulp cell pyroptosis, the safety and efficacy of rapamycin in clinical treatment still requires further investigation. Based on the current experimental design, it is difficult to exclude the direct protective effect of rapamycin-induced autophagy independent of pyroptosis. Autophagy may be one of several relevant secondary effects of mTOR inhibition, and the role of rapamycin in this system needs to be further studied. In addition, the current study only compared the effects of LPS on cells with the baseline, but not with controls incubated with medium over equivalent time. Finally, the photomicrographs of the LPS treated cells were not presented.

In conclusion, the present study demonstrated that LPS treatment may induce a low level of autophagy, which may be a self-help strategy in dental pulp cells. These results highlighted for the first time the potential of rapamycin in pulpitis therapy.

\section{Acknowledgements}

Not applicable.

\section{Funding}

This work was supported by Jiangsu Provincial Key Research Development Program (Social Development) (grant no. BE2016796).

\section{Availability of data and materials}

The datasets used and/or analyzed during the current study are available from the corresponding author on reasonable request.

\section{Authors' contributions}

YG and XY made substantial contributions to conception and design; YL, FG, JY, CY and YZ were responsible for data acquisition, analysis and interpretation; and JY and CY drafted the article or critically revising it for important intellectual content. All authors agreed to be accountable for all aspects of the work in ensuring that questions related to the accuracy or integrity of the work are appropriately investigated and resolved and all authors gave final approval of the version to be published.

\section{Ethics approval and consent to participate}

The study protocol was approved by the Ethical Committee Department of Nanjing Medical University (cat. no: NM20180510). Written informed consents were obtained from 
the children's parents or legal representatives. All procedures involving human participants were in accordance with the ethical standards of the institutional and/or national research committee and with the 1964 Helsinki declaration and its later amendments or comparable ethical standards.

\section{Patient consent for publication}

Not applicable.

\section{Competing interests}

The authors declare that they have no competing interests.

\section{References}

1. Hahn CL and Liewehr FR: Relationships between caries bacteria, host responses, and clinical signs and symptoms of pulpitis. J Endod 33: 213-219, 2007.

2. Jontell M, Okiji T, Dahlgren U and Bergenholtz G: Immune defense mechanisms of the dental pulp. Crit Rev Oral Biol Med 9: 179-200, 1998.

3. Zhang A, Wang P, Ma X, Yin X, Li J, Wang H, Jiang W, Jia Q and Ni L: Mechanisms that lead to the regulation of NLRP3 inflammasome expression and activation in human dental pulp fibroblasts. Mol Immunol 66: 253-262, 2015.

4. Sood AK, Burbank AJ, Duran CG, Enders K, Zhou H, Peden DB and Hernandez ML: Gamma tocopherol effect on LPS-induced sputum neutrophilia is not modified by BMI or GSTM1 genotype. J Allergy Clin Immunol 143: 1937-1939, 2019.

5. Tang Y, Wang C, Wang Y, Zhang J, Wang F, Li L, Meng X, Li G, Li Y and Wang L: Isoliquiritigenin attenuates LPS-induced AKI by suppression of inflammation involving NF- $\mathrm{BB}$ pathway. Am J Transl Res 10: 4141-4151, 2018.

6. Li S, Ning LG, Lou XH and Xu GQ: Necroptosis in inflammatory bowel disease and other intestinal diseases. World J Clin Cases 6: 745-752, 2018.

7. Chimenti MS, Sunzini F, Fiorucci L, Botti E, Fonti GL, Conigliaro P, Triggianese P, Costa L, Caso F, Giunta A, et al: Potential role of cytochrome $\mathrm{c}$ and tryptase in psoriasis and psoriatic arthritis pathogenesis: Focus on resistance to apoptosis and oxidative stress. Front Immunol 9: 2363, 2018.

8. Brough D and Rothwell NJ: Caspase-1-dependent processing of pro-interleukin-1beta is cytosolic and precedes cell death. J Cell Sci 120: 772-781, 2007.

9. He Y, Hara H and Núñez G: Mechanism and regulation of NLRP3 inflammasome activation. Trends Biochem Sci 41: 1012-1021, 2016

10. Jiang W, Lv H, Wang H, Wang D, Sun S, Jia Q, Wang P, Song B and Ni L: Activation of the NLRP3/caspase-1 inflammasome in human dental pulp tissue and human dental pulp fibroblasts. Cell Tissue Res 361: 541-555, 2015.

11. Zhang $\mathrm{H}$ and Sun SC: NF- $\kappa B$ in inflammation and renal diseases. Cell Biosci 5: 63, 2015

12. Bhatt D and Ghosh S: Regulation of the NF- $\mathrm{BB}$-mediated transcription of inflammatory genes. Front Immunol 5: 71, 2014.

13. Denton D, Xu T and Kumar S: Autophagy as a pro-death pathway. Immunol Cell Biol 93: 35-42, 2015.

14. Guan JL, Simon AK, Prescott M, Menendez JA, Liu F, Wang F, Wang C, Wolvetang E, Vazquez-Martin A and Zhang J: Autophagy in stem cells. Autophagy 9: 830-849, 2013.

15. Nikoletopoulou V, Papandreou ME and Tavernarakis $\mathrm{N}$ : Autophagy in the physiology and pathology of the central nervous system. Cell Death Differ 22: 398-407, 2015.

16. Levine B, Mizushima N and Virgin HW: Autophagy in immunity and inflammation. Nature 469: 323-335, 2011.

17. Levine B and Klionsky DJ: Development by self-digestion: Molecular mechanisms and biological functions of autophagy. Dev Cell 6: 463-477, 2004

18. Deretic V, Jiang S and Dupont N: Autophagy intersections with conventional and unconventional secretion in tissue development, remodeling and inflammation. Trends Cell Biol 22: 397-406, 2012.
19. Couve E, Osorio R and Schmachtenberg O: The amazing odontoblast: Activity, autophagy, and aging. J Dent Res 92: 765-772, 2013.

20. Yang J, Wan C, Nie S, Jian S, Sun Z, Zhang L and Chen Z: Localization of Beclin1 in mouse developing tooth germs: Possible implication of the interrelation between autophagy and apoptosis. J Mol Histol 44: 619-627, 2013.

21. Mankowski RT, Ahmed S, Beaver T, Dirain M, Han C, Hess P, Martin T, Smith BK, Someya S, Leeuwenburgh C and Martin AD: Intraoperative hemidiaphragm electrical stimulation reduces oxidative stress and upregulates autophagy in surgery patients undergoing mechanical ventilation: Exploratory study. J Transl Med 14: 305, 2016.

22. Caramés B, Taniguchi N, Otsuki S, Blanco FJ and Lotz M: Autophagy is a protective mechanism in normal cartilage, and its aging-related loss is linked with cell death and osteoarthritis. Arthritis Rheum 62: 791-801, 2010.

23. Pei F, Lin H, Liu H, Li L, Zhang L and Chen Z: Dual role of autophagy in lipopolysaccharide-induced preodontoblastic cells. J Dent Res 94: 175-182, 2015.

24. Meng N, Wu L, Gao J, Zhao J, Su L, Su H, Zhang S and Miao J: Lipopolysaccharide induces autophagy through BIRC2 in human umbilical vein endothelial cells. J Cell Physiol 225: 174-179, 2010.

25. Hickson-Bick DL, Jones C and Buja LM: Stimulation of mitochondrial biogenesis and autophagy by lipopolysaccharide in the neonatal rat cardiomyocyte protects against programmed cell death. J Mol Cell Cardiol 44: 411-418, 2008.

26. Xu Y, Kim SO, Li Y and Han J: Autophagy contributes to caspase-independent macrophage cell death. J Biol Chem 281: 19179-19187, 2006

27. Jung JY, Woo SM, Kim WJ, Lee BN, Nör JE, Min KS, Choi CH, Koh JT, Lee KJ and Hwang YC: Simvastatin inhibits the expression of inflammatory cytokines and cell adhesion molecules induced by LPS in human dental pulp cells. Int Endod J 50: 377-386, 2017.

28. Li H, Gao A, Feng D, Wang Y, Zhang L, Cui Y, Li B, Wang Z and Chen G: Evaluation of the protective potential of brain microvascular endothelial cell autophagy on blood-brain barrier integrity during experimental cerebral ischemia-reperfusion injury. Transl Stroke Res 5: 618-626, 2014.

29. Kim MJ, Kim EH, Pun NT, Chang JH, Kim JA, Jeong JH, Choi DY, Kim SH and Park PH: Globular adiponectin inhibits lipopolysaccharide-primed inflammasomes activation in macrophages via autophagy induction: The critical role of AMPK signaling. Int J Mol Sci 18: E1275, 2017.

30. Zhan FL, Liu XY and Wang XB: The role of MicroRNA-143-5p in the differentiation of dental pulp stem cells into odontoblasts by targeting Runx 2 via the OPG/RANKL signaling pathway. J Cell Biochem 119: 536-546, 2018.

31. Dupont N, Jiang S, Pilli M, Ornatowski W, Bhattacharya D and Deretic V: Autophagy-based unconventional secretory pathway for extracellular delivery of IL-1 $\beta$. EMBO J 30: 4701-4711, 2011.

32. Murai H, Okazaki S, Hayashi H, Kawakita A, Hosoki K, Yasutomi M, Sur S and Ohshima Y: Alternaria extract activates autophagy that induces IL-18 release from airway epithelial cells. Biochem Biophys Res Commun 464: 969-974, 2015.

33. Lin YC, Huang DY, Wang JS, Lin YL, Hsieh SL, Huang KC and Lin WW: Syk is involved in NLRP3 inflammasome-mediated caspase-1 activation through adaptor ASC phosphorylation and enhanced oligomerization. J Leukoc Biol 97: 825-835, 2015.

34. Wu J, Fernandes-Alnemri T and Alnemri ES: Involvement of the AIM2, NLRC4, and NLRP3 inflammasomes in caspase-1 activation by Listeria monocytogenes. J Clin Immunol 30: 693-702, 2010.

35. Miao EA, Rajan JV and Aderem A: Caspase-1-induced pyroptotic cell death. Immunol Rev 243: 206-214, 2011.

36. Couve E and Schmachtenberg O: Autophagic activity and aging in human odontoblasts. J Dent Res 90: 523-528, 2011.

37. Couve E, Osorio R and Schmachtenberg O: Mitochondrial autophagy and lipofuscin accumulation in aging odontoblasts. J Dent Res 91: 696-701, 2012.

38. Li L, Zhu YQ, Jiang L and Peng W: Increased autophagic activity in senescent human dental pulp cells. Int Endod J 45: 1074-1079, 2012.

39. Lee YH, Lee HY, Kim TG, Lee NH, Yu MK and Yi HK: PPAR maintains homeostasis through autophagy regulation in dental pulp. J Dent Res 94: 729-737, 2015. 
40. Park SY, Sun EG, Lee Y, Kim MS, Kim JH, Kim WJ and Jung JY: Autophagy induction plays a protective role against hypoxic stress in human dental pulp cells. J Cell Biochem 119: 1992-2002, 2018.

41. Pantovic A, Krstic A, Janjetovic K, Kocic J, Harhaji-Trajkovic L, Bugarski D and Trajkovic V: Coordinated time-dependent modulation of AMPK/Akt/mTOR signaling and autophagy controls osteogenic differentiation of human mesenchymal stem cells. Bone 52: 524-531, 2013.

42. Chang X, He H, Zhu L, Gao J, Wei T, Ma Z and Yan T: Protective effect of apigenin on Freund's complete adjuvant-induced arthritis in rats via inhibiting $\mathrm{P} 2 \mathrm{X} 7 / \mathrm{NF}-\kappa \mathrm{B}$ pathway. Chem Biol Interact 236: 41-46, 2015.

43. Criollo A, Chereau F, Malik SA, Niso-Santano M, Mariño G, Galluzzi L, Maiuri MC, Baud V and Kroemer G: Autophagy is required for the activation of NFkappaB. Cell Cycle 11: 194-199, 2012.

44. Schlottmann S, Buback F, Stahl B, Meierhenrich R, Walter P, Georgieff $M$ and Senftleben U: Prolonged classical NF-kappaB activation prevents autophagy upon E. coli stimulation in vitro: A potential resolving mechanism of inflammation. Mediators Inflamm 2008: 725854, 2008.

45. Jia X, Cao B, An Y, Zhang X and Wang C: Rapamycin ameliorates lipopolysaccharide-induced acute lung injury by inhibiting IL-1 $\beta$ and IL-18 production. Int Immunopharmacol 67: 211-219, 2019.

46. Meijer AJ and Codogno P: Regulation and role of autophagy in mammalian cells. Int J Biochem Cell Biol 36: 2445-2462, 2004.

47. Liu YC, Gao XX, Chen L and You XQ: Rapamycin suppresses $\mathrm{A} \beta_{25-35^{-}}$or LPS-induced neuronal inflammation via modulation of NF-кB signaling. Neuroscience 355: 188-199, 2017.
48. Huang HY, Chang HF, Tsai MJ, Chen JS and Wang MJ: 6-Mercaptopurine attenuates tumor necrosis factor- $\alpha$ production in microglia through Nur77-mediated transrepression and PI3K/Akt/mTOR signaling-mediated translational regulation. J Neuroinflammation 13: 78, 2016.

49. Vangan N, Cao Y, Jia X, Bao W, Wang Y, He Q, Binderiya U, Feng X, Li T, Hao H and Wang Z: mTORC1 mediates peptidoglycan induced inflammatory cytokines expression and NF- $\kappa \mathrm{B}$ activation in macrophages. Microb Pathog 99: 111-118, 2016.

50. Fielhaber JA, Carroll SF, Dydensborg AB, Shourian M, Triantafillopoulos A, Harel S, Hussain SN, Bouchard M, Qureshi ST and Kristof AS: Inhibition of mammalian target of rapamycin augments lipopolysaccharide-induced lung injury and apoptosis. J Immunol 188: 4535-4542, 2012.

51. Yue Y, Wang Y, Li D, Song Z, Jiao H and Lin H: A central role for the mammalian target of rapamycin in LPS-induced anorexia in mice. J Endocrinol 224: 37-47, 2015.

52. Mengke NS, Hu B, Han QP, Deng YY, Fang M, Xie D, Li A and Zeng HK: Rapamycin inhibits lipopolysaccharide-induced neuroinflammation in vitro and in vivo. Mol Med Rep 14: 4957-4966, 2016.

53. Okamoto T, Ozawa Y, Kamoshita M, Osada H, Toda E, Kurihara T, Nagai N, Umezawa K and Tsubota K: The neuroprotective effect of rapamycin as a modulator of the mTOR-NF- $\kappa \mathrm{B}$ axis during retinal inflammation. PLoS One 11: e0146517, 2016.

(i) 9 This work is licensed under a Creative Commons Attribution-NonCommercial-NoDerivatives 4.0 International (CC BY-NC-ND 4.0) License. 